\title{
Role of internal controls in business resilience and growth of small businesses in Gaborone
}

\author{
Onthatile M. Kelebetse \\ Faculty of Business, \\ University of Botswana, Gaborone, Botswana \\ Suryakanthi Tangirala \\ Faculty of Business, \\ University of Botswana, Gaborone, Botswana \\ Tiroyamodimo Sethate \\ Faculty of Business, \\ University of Botswana, Gaborone, Botswana \\ Gangappa Kuruba \\ Faculty of Business, \\ University of Botswana, Gaborone, Botswana
}

\begin{abstract}
This study was carried out to evaluate whether internal controls have an implication in the resilience and growth of small businesses in Gaborone. The study was driven by the fact that small managed businesses lack internal controls in their businesses thus hindering their growth which has a negative impact on their lifespan and sustainability. The scope of the study was limited to small businesses in Gaborone. The outcome of the study will be useful by relevant authorities by knowing the factors that affect the use of internal controls so as to put controls in place and the results will help to scrutinize the organizational internal controls thus paving way for growth and survival. Primary data was used, which were questionnaires handed out to small businesses and the data collected from the companies under study was calculated and analysed using Microsoft Excel. Data processed was presented in bar charts, pie charts and tables. The results showed that internal controls have an effect in the resilience and growth of small businesses.
\end{abstract}

Keywords: Internal Controls, risks, weakness

\section{INTRODUCTION}

Internal controls consist of policies and procedures designed to provide management with reasonable assurance about the achievement of the entity's objectives with regard to the reliability of operations and compliance with applicable laws and regulations[1]. Internal control's responsibility is to ensure that corporate objectives are being achieved with reliable financial reporting, efficient operations and compliance with the country laws. It is the responsibility of the board of director's and corporate management to ensure that internal controls are in place. According to American Institute of Certified Public Accountants;

"Internal control is a process effected by plan management and other personnel, and those charged with governance, and designed to provide reasonable assurance regarding the achievement of objectives in the reliability of financial reporting"[2]. 
The Committee of Sponsoring Organizations (COSO) unveiled the internal control system components in 1992, mainly to address the fraudulent scandals which brought down major corporations in the 80's [3]. [4] Presented an updated internal control integrated framework in 2013 which enables organizations to effectively and efficiently implement internal controls to achieve organizational objectives and to adapt to changes in the business and operating environments. Buben [5] illustrates that Implementing internal controls provide reasonable assurance of i) Effectiveness and assurance of operations, ii) reliability of financial reporting and iii) compliance with laws and procedures; combining all these facilitate safeguarding of assets as depicted in Figure 1.

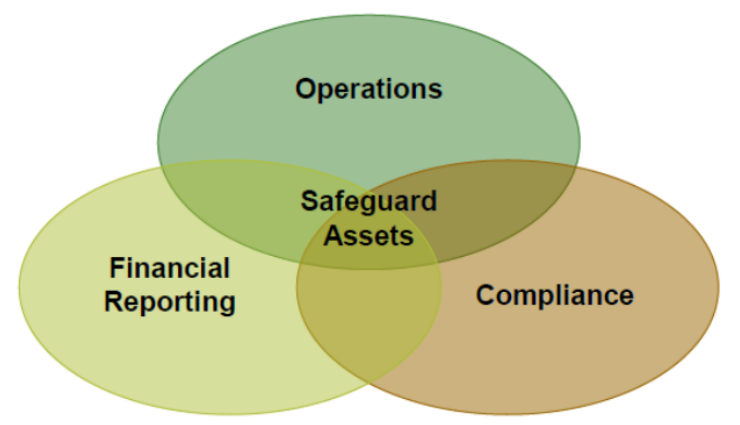

Figure 1: Internal Controls (original source: [5])

According to Cunningham [6] internal controls assist the organization in meeting its goals and objectives, therefore, an organization without internal control means that organization would be without control toward its desired target, and will soon fall off course, away from the companies cooperate objective. Internal controls have to be used consistently and management has to make decisions on which internal controls to adopt as a small business. Treba[7] alludes that proper controls are management's primary responsibility. Those with seniority duties have to appropriately conduct business hence their delegates will also do the same, therefore working for a common goal of ensuring that the business has competitive advantage and hence increasing chances of growth.

Botswana Institute for Development Policy Analysis (BIDPA) stated that small and medium enterprises (SME's), if properly natured, empower the country's economy [8]. The use and maintenance of resources of small businesses depend on successful execution of internal controls [9]. Globally, internal control failure among small businesses often leads to loss of assets, fraud, waste, mismanagement, inefficiency, loss of client assurance, and failure to achieve business goals. Although Small medium and micro enterprises (SMME's) have a significant impact on fostering economic growth, this sector is faced with many challenges in Botswana. It is noted that 70\% of SMME's fail with in first 18 months of operation. Some of the many challenges include "lack of finance, prohibitive costs in acquiring and effectively utilizing appropriate technology and limited managerial skills as well as little or no business acumen"[7].Therefore, it is strongly recommended to implement Internal controls to avoid failures.

Policies and procedures set up by internal controls also help the corporate leadership to manage risk which may hinder the corporate performance or challenge the existence of that company[10]. These policies when adopted by an entity, can ensure that an organization`s transactions are processed in the appropriate manner to avoid waste, theft and misuse of organization's resources[11]. It is thus recommended to enhance control environment to reduce fraud and improve the company's financial performance. Therefore, the research is conducted with the following objectives:

- To find whether internal controls are in place in small businesses 
- To study the impact of Internal controls on effective and efficient operations of organizations

- To determine factors that inhibits small businesses from implementing internal controls

- To Investigate the compliance of Internal controls with changing laws and regulations

\section{LITERATURE REVIEW}

Internal controls consists of policies and procedures designed to provide management with reasonable assurance about the achievement of the entity's objectives with regard to the reliability of operations and compliance with applicable laws and regulations [1],[4]. These policies are crucial in setting direction for execution of corporate tasks using the right methods and procedures. Governance and execution of internal controls requires a composite of managerial functions and skills ranging from operational, financial reporting, auditing as well as performance specialists[12]. When objectively applied, the internal controls assure of reliable financial reporting. This enhances management decision making process and promote adherence to applicable laws and regulations at the same time minimising the risks[2] .

As defined by Watters [13] business resilience is the ability an organization has to quickly adapt to disruptions while maintaining continuous business operations and safeguarding people, assets and overall brand equity. Businesses should be ready for sudden shocks such as cybersecurity breaches, fraud and Foreign Corrupt Practices Act (FCPA) violations and require organizations have a mitigation plan ready to handle the risk. Risk events seem more frequent and more public than ever because of internet and social media and organizations should respond quickly to protect its reputation. Regulatory activities increased over the last several years in response to the events in the marketplace. Moreover, the change has significantly affected organizations' internal controls. In 2013, COSO released updated version of its internal controls in response to changes in the business models to address risk management and fraud prevention[13]. Study by Sathyamoorthi [14] revealed that it is important to have internal control system over all business activities and a well-designed and properly implemented control system ensures protection of organization's resources against risk, waste and fraud. H1: Internal controls have significant impact on business resilience and growth in organizations

A study by [15]showed a positive relationship between internal control and company performance in their study on sugarcane out grower companies in Kenya[15]. This reiterates the importance of internal control to corporate performance as echoed by multiple scholars. Eniola and Akinselure [16] also agree that effective internal control significantly reduces fraud and improves financial performance. Over and above internal control being effective and improving performance, it has to be cost effective[17]. Expensive internal controls would either deter companies from using them, or not be affordable for a lot of companies, especially the small companies. Another study by Sankoloba and Swami reveal that implementing internal controls is moderately expensive [8].

H2: The major inhibition of having internal control in small businesses is the costs associated with the implementation of internal controls.

Internal controls become useless when management's practices are not aligned with strategic objectives. According to Baysinger and Hoskisson [18], management should set and implement controls in line with strategic plans for the organisation. So the composition of the boards of directors has a direct bearing on the corporate strategy, as well as the types of internal controls being implemented. 
Thuy [19] further states that the foundation for effective internal control is in the ethical behavior of the management. Other employees mimic what they see the management doing. This brings into the fore the standards set by the corporate leadership and their integrity. The Bank of Botswana Internal Audit Charter [20] postulates that it is the management's responsibility to set operating standards to measure an entity`s efficient and economical use of resources. It is important then to have management who are guided by ethical values and high degree of integrity. Ifezue [21] noted that senior management has responsibility for implementing good internal controls; otherwise the employees can work with clients to commit fraudulent activities. Employees also have a great bearing on the success of implementation of an effective controls environment. But management has to take the lead role. Management should have the competency, knowledge in the area of rights, responsibilities and skills [22] to successfully implement internal controls.

Hall [3] noted the significant evolution of internal controls, they are no longer manual; computer systems have been put in place. Though convenient, they come at a cost, especially securing information resources. This also talks to staff training which also hikes the price of internal controls. Lack of resources/knowledge can hinder small businesses' ability to implement internal controls and hire additional personnel in order to allow segregation of incompatible duties.

H3: Lack of resources/knowledge inhibit the implementation of internal controls in small businesses

\section{METHODOLOGY}

This section outlines the period of research, the data collection procedure, methods for data processing and scope of the study.

\section{Period of research}

The research will be carried out from $8^{\text {th }}$ of October 2018 to 6 May 2019. Data collection was done not later than the $4^{\text {th }}$ of February 2019.

\section{Data collection procedure}

This study is based on primary research. According to [23] primary data is data that is collected and used for the first time without interpretation or assertions of an official opinion. In this research questionnaires were used to collect data. The questionnaire has both closed ended as well as open ended Questions. Respondents answer the items using a five-point Likert scale to express their levels of agreement for closed ended questions

\section{Data processing}

Data processing involved processes that converted data into information that could be easily interpreted by the reader. Data was coded and converted into useful data and analyzed using Microsoft Excel. The analyzed data was presented in graphs, charts and tables.

\section{Scope of the study}

This research is based on small businesses in Gaborone, Botswana's capital city. The small businesses targeted range from small restaurants, hair salons, construction companies, retailers, bakeries.

\section{DATA ANALYSIS}

A total of 80 questionnaires were distributed to small businesses located in Gaborone area, 8 were sent through email and others were given by hand. 57 responses were received and 23 questionnaires were not returned which accounts to $71.2 \%$ response rate. The data was analysed using excel and is graphically presented in the form of charts, tables and graphs. 


\section{Existence of Internal controls in SME's}

Out of 57 small businesses that responded, 34 (59.6\%) of them were sole proprietors, 19 (33.3\%) were partnerships, $3(5.3 \%)$ being corporation and $1(1.8 \%)$ is other (limited liability). Of the fifty- seven small businesses that were part of the study, 39 (68\%) businesses indicated that they had internal controls in place in their organizations whereas 18 (32\%) indicated that they had no internal controls in place.

\section{Types of Internal controls in SME's}

Out of 57 small businesses that responded, 34 (59.6\%) of them were sole proprietors, 19 (33.3\%) were partnerships, $3(5.3 \%)$ being corporation and $1(1.8 \%)$ is other (limited liability). Of the fifty- seven small businesses that were part of the study, 39 (68\%) businesses indicated that they had internal controls in place in their organizations whereas 18 (32\%) indicated that they had no internal controls in place.

Table 2 indicates that out of 39 of the respondents who indicated that they have internal controls in their businesses, 7 (17.9\%) of them use adequate documentation and records, $11(28.2 \%)$ articulated that they use proper authorization of transactions, $3(7.7 \%)$ use physical control over assets and records, 17 (43.6\%) use them for segregation of duties, while only one indicated that they are using other (independent checks of performance).

Table 1: Types of Internal controls in Businesses

\begin{tabular}{|l|c|c|}
\hline \multirow{2}{*}{\multicolumn{1}{|c|}{ Internal controls }} & \multicolumn{2}{c|}{ Responses } \\
\cline { 2 - 3 } & Number & percentage \\
\hline Adequate documentation and records & 7 & 17.9 \\
\hline Proper authorization of transactions & 11 & 28.2 \\
\hline Physical control over assets and records & 3 & 7.7 \\
\hline Segregation of duties & 17 & 43.6 \\
\hline Other & 1 & 2.6 \\
\hline
\end{tabular}

\section{Importance of Internal controls in SME's}

Out of 57 respondents, 41 (71.9\%) strongly agree that internal controls are important in a business, thirteen $(22.8 \%)$ agree that internal controls are important in a business, two of the respondents are neutral on the subject while only one individual disagree that internal controls are important in a business as depicted by pie chart in Figure 2 .

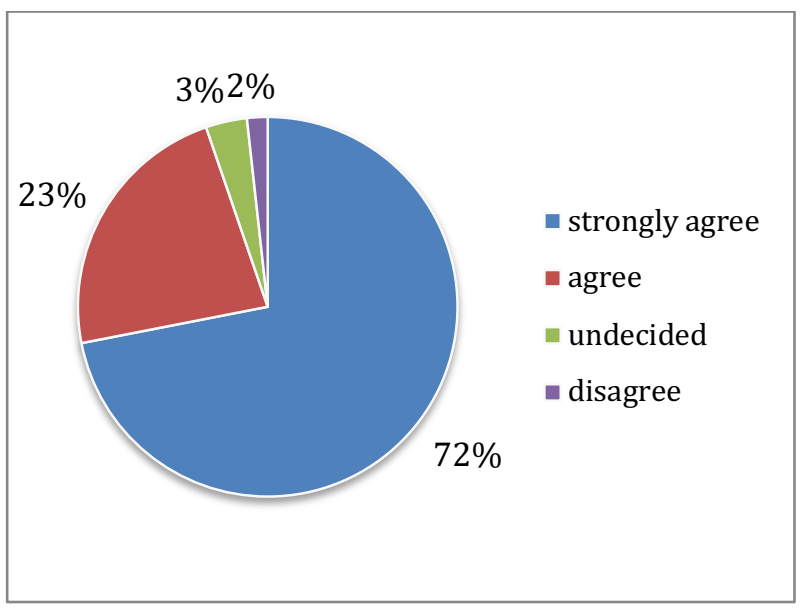

Figure 2: Importance of Internal Controls 


\section{Impact of Internal controls in promoting efficient and effective operations of SME's Existence of accounting procedures make accounting true and fair}

The pie chart demonstrates that from the businesses approached, 6 (10.5\%) strongly disagree with the statement that says there are accounting procedures which make accounting true and fair and $3(5.3 \%)$ of the respondents disagree. Seven $(12.3 \%)$ individuals remained undecided, $25(43.9 \%)$ agreed that there are accounting procedures which make accounting true and fair, while $16(28.1 \%)$ strongly agreed to the statement

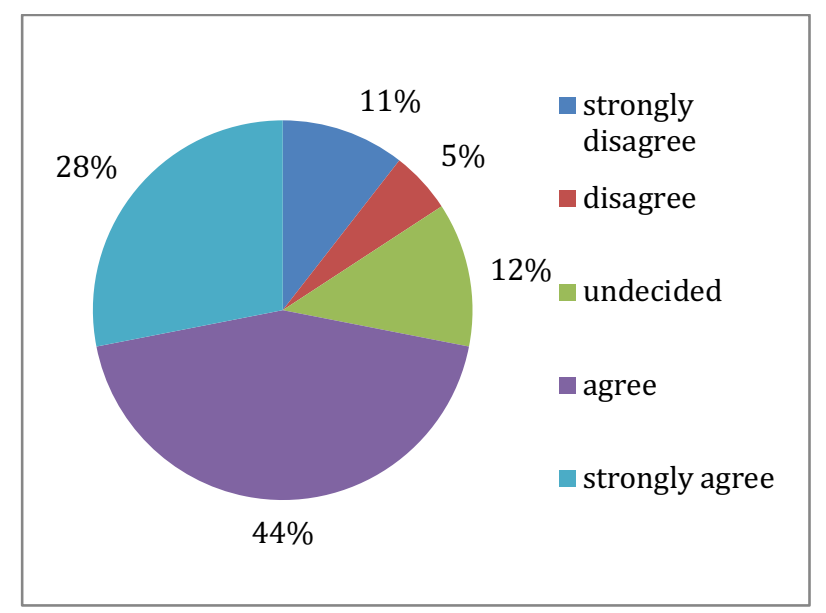

Figure 3: Existence of control procedures to make accounting true and fair

\section{Internal controls ensure reliability and integrity of financial reporting}

Internal controls ensure management has accurate, timely and complete information. Existences of procedures ensure integrity of financial reporting. As shown in Figure 4, out of 57 businesses, 2 (3.5\%) strongly disagreed with the statement saying there are procedures ensuring the accuracy, relevance and reliability of information which provides a basis for financial reporting. Four (7.0\%) disagreed with the statement, 11 (19.3\%) respondents were undecided while 22 (38.6\%) agreed that there are procedures ensuring the accuracy, relevance and reliability of information which provides a basis for financial reporting. Eighteen (31.6\%) individuals strongly agreed with the statement.

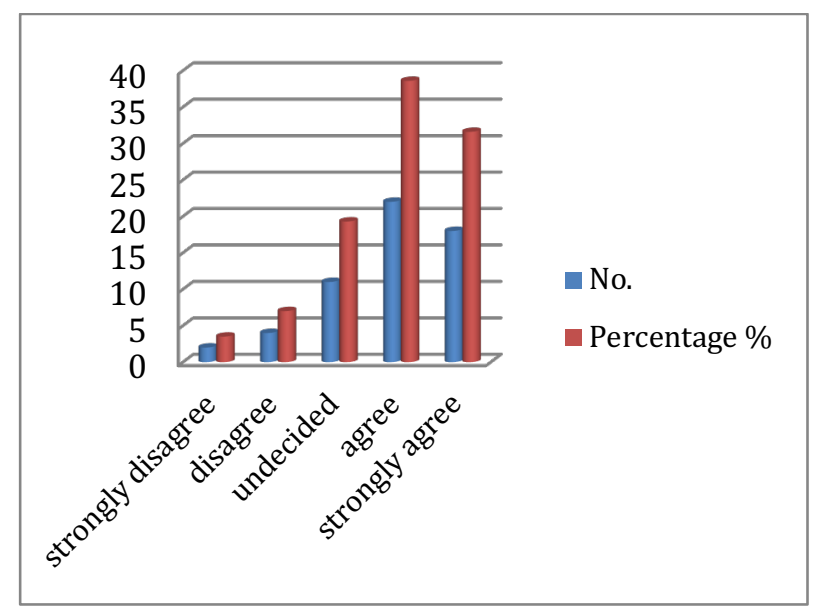

Figure 4: Existence of procedures ensuring accuracy, relevance and reliability of information

\section{Impact of ineffective Internal controls on Asset Management}

The bar graph above illustrates that the most affected area in businesses covered in the study is the asset area. Misappropriation of assets 28 (49.1\%) is posing greater risks than the others, followed by embezzlement with 22 (38.6\%). Five respondents indicated that ineffective internal controls cause pilferage while $2(3.5 \%)$ individuals fall under other. 


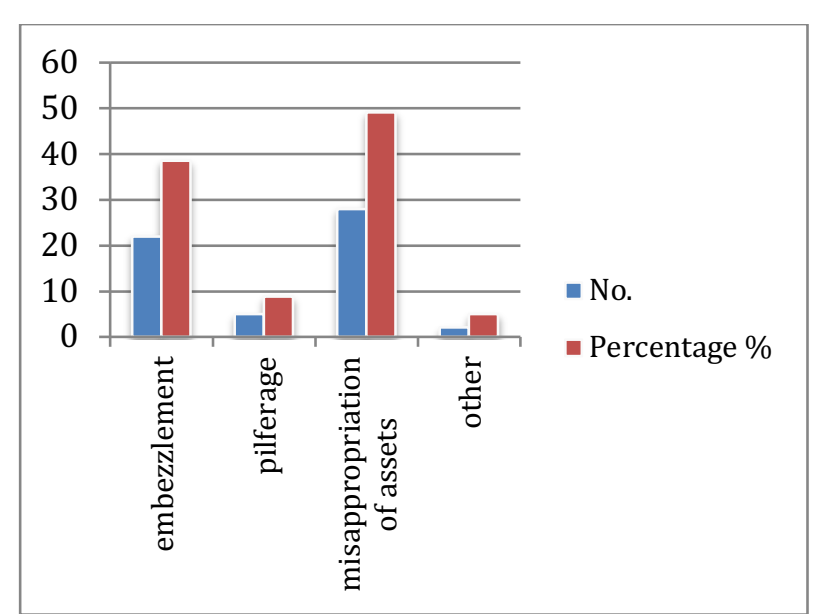

Figure 5: Impact of ineffective internal controls on Asset Management

\section{Impact of internal control on business resilience and growth}

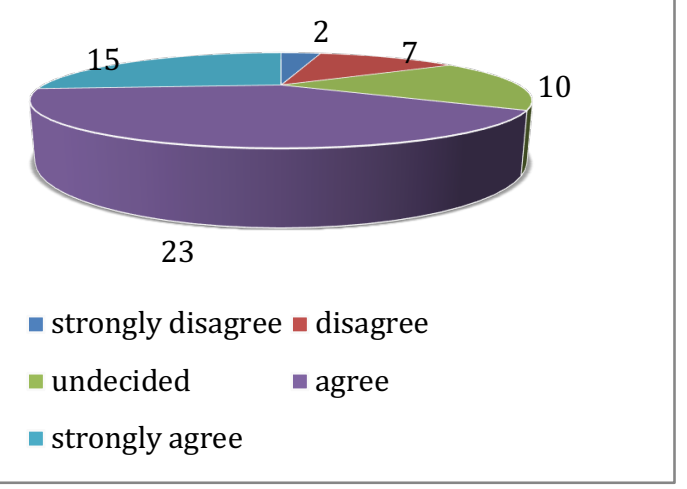

Figure 6: Impact of Internal controls on Business resilience and growth

As shown in Figure 6, out of the 57 respondents, 15 (26.3\%) strongly agree with the statement that effective implementation of internal controls has significant impact on business resilience and growth. Twenty-three (40.4\%) agree with the above statement, 10 (17.5\%) of the respondents remained undecided on the matter. Seven (12.3\%) disagreed with the statement and $2(3.5 \%)$ individuals strongly disagreed.

\section{Internal controls compliance with changing laws and regulations:}

Internal controls help to ensure that business is in compliance with applicable laws and regulations affecting their business operations. Out of 57, 8 (14.0\%) respondents strongly agree that processes and controls are constantly updated according to changing laws and regulations, Twenty-three (40.4\%) agree while $20(35.1 \%)$ remained undecided. Those who disagreed with the statement were $5(8.8 \%)$ and only one individual strongly disagreed as shown in figure 7. 


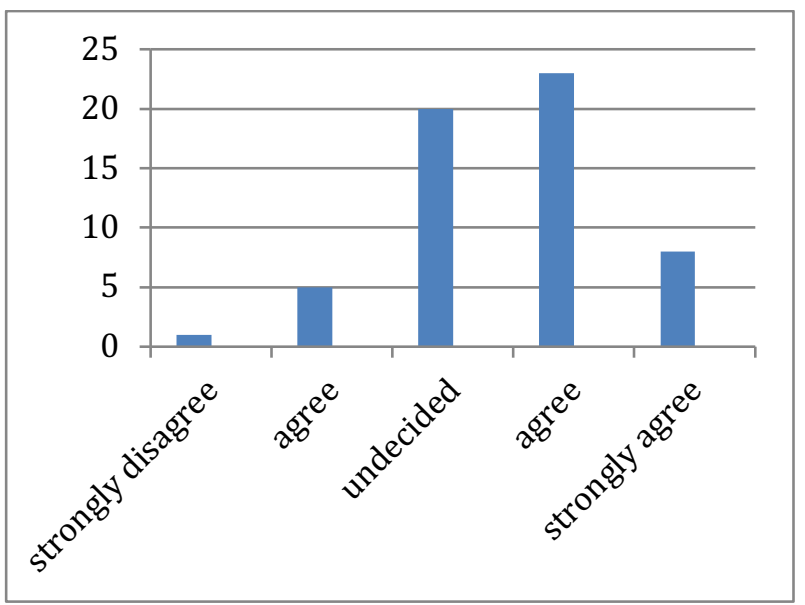

Figure 7: Update of Internal controls in line with Risks

\section{Analysis of Open ended questions:}

\section{Factors that inhibit implementation of internal controls.}

Based on responses received from open ended questions, 28 (49\%) of the respondents indicated that factors inhibiting the use of controls in their organizations is the high costs associated with the implementation of internal controls. From the responses, $17(30 \%)$ stated that the lack of knowledge about the controls curb the use of controls, while 12 (21\%) did not respond to the question.

\section{Business resilience and growth has to do with effective internal controls}

From the study, 21 respondents stated that their businesses are resilience because internal controls help prevent fraud, waste, and abuse of organizational resources. According to the study, nine responded that controls advance efficiency in daily operations of the firm and ensure that management's objectives and decisions are being followed, and this strengthens the sustainability and continuity of their respective companies. Twenty-seven individuals did not respond to the question.

\section{Systems put in place to detect problems and prevent problems of ineffective internal controls.}

Thirteen responses indicated that embezzlement can be reduced or managed by keeping proper records and documents. They further suggested that invoices should be pre-numbered systematically in order to avoid issues of duplication. Fifteen individuals stated that in order to prevent and minimize misappropriation of assets such as company vehicles, the vehicles of the company track systems have been installed in the cars to ensure employees travel to the designated areas only. Also regular stock takes and examination of equipment should be ensured.

Four respondents indicated that limited access to petty cash should be maintained to avoid lapping and kitting, as well as avoiding to give one employee absolute control over one process for example, authorization of sales and accounts receivables. Two of the companies which have experienced the problem of pilferage stated installation of CCTV cameras and regular stock counts to know exactly the number of items in the stock bins. Regular changes to sales and purchases should be noted to ensure quick and fast responses to any deviations that may occur.

\section{Measures that organizations can use internal control to enhance reliance and growth.}

Concerning measures that can be used to deter instances of error and fraud, 6 responded that preventive activities such as thorough documentation and authorization practices must be put 
in place. Document the process for review, including what reports and payments are due and when, who will report to whom and who is responsible for what. Eleven indicated that supervision of employees must be put in place in order to ensure accurate attendance, time and record keeping is maintained while 40 individuals did not respond to the question.

\section{Key findings on Objectives}

\section{FINDINGS}

The first objective of the study was to find whether internal controls are in place in SME's in Gaborone area, the results show that SME's in Gaborone have internal controls in place for their business operations, albeit they are using them in limited extent. Thirty-nine (68\%) of small businesses indicated that they had internal controls in place in their organizations while eighteen (32\%) stated that they had no controls in place.

The second objective of the research is to study the impact of internal controls on effective and efficient operation of organisations. The results show that $72 \%$ of the respondents supported the view that internal controls promote efficient and effective operations of organisations. Internal controls in the form of accounting procedures make accounting true and fair. They ensure reliability and integrity of financial reporting. In addition, it is also believed that ineffective internal controls have a negative impact on asset management, especially in the form of embezzlement of assets.

Third objective is to determine factors that inhibit small businesses from implementing internal controls. The findings show that $49 \%$ of respondents indicated that high implementation costs hinder them from implementing internal controls while $30 \%$ respondents stated that lack of knowledge/training on controls inhibits them to practice internal controls in their respective businesses.

Fourth objective is to investigate the compliance of internal controls with changing laws and regulations. The results show that 54\% of respondents agreed that processes and controls are constantly updated as per the changing laws and regulations. Others either disagreed or remained neutral.

\section{Key findings on hypotheses statements.}

The findings are in line with the literature

H1: Internal controls have significant impact on business resilience and growth in organizations $\mathrm{H} 1$ is deemed to be true as majority (95\%) percent of the respondents agreed that internal controls play a crucial role in business operation thus have a positive factor in the resilience and growth of small businesses as depicted in figure 2. They further stated that their businesses are resilience because internal controls help prevent fraud, waste, and abuse of organizational resources

H2: The major inhibition of having internal control in small businesses is the costs associated with the implementation of internal controls.

H2 is proved to be true as (49\%) of the respondents indicated that factors inhibiting the use of controls in their organizations is the high costs associated with the implementation of internal controls

H3: Lack of resources/knowledge inhibit the implementation of internal controls in small businesses

$\mathrm{H} 3$ is observed to be true as $(30 \%)$ of the respondents stated that the lack of knowledge about the controls curb the use of controls 


\section{CONCLUSIONS \& RECOMMENDATIONS}

Internal control procedures are fundamental and important steps in reducing theft and fraud. Small businesses should have internal controls in place to ensure that the organization operates efficiently and effectively. These controls are designed to monitor the firm's assets, prevent fraud, minimise errors, authenticate the accuracy and reliability of accounting data and promote the efficient operation of the firm while ensuring that established management practices are followed. It is evident that small businesses in Gaborone have internal controls as businesses which voted for the subject were more than those who voted against the issue of having internal controls.

From this research the scholar identified that high implementation costs and lack of knowledge/training are the two main factors that restrict most of the businesses to enforce them in their respective organizations. Controlling implementation costs may not be feasible all the time but updating employee knowledge on internal controls can be improved with adequate training. In this era of consistent competitiveness among firms, small businesses should train their employees on internal controls as play a pivotal role in resilience and growth of small businesses. Policies regarding internal controls in businesses must be made clear so that all employees are aware of them. Workshops and seminars should be initiated to educate both employers and employees about internal controls. Incentives must be given to employees who uphold the company internal controls hence promoting the spirit of working towards achieving a common goal.

\section{References}

Arens, A.A., R.J. Elder, and M.S. Beasley, Auditing and Assurance Services: An Intergrated Approach2012, United Kingdom: Pearson.

The Importance of Internal Control in financial reporting and safegurading plan assets, in www.aicpa.org2014.

Hall, J.A., Infromation Technology Auditing2016, Boston: Cengage Learning.

Internal Control - Integrated Framework, in www.coso.org2013.

Amy Buben, Fraud Risks and Why Internal Controls are Important, 2017,Feb 9, Yeo \& Yeo CPA's and business consultants.

Cunningham, L.A., The appeal and limits of internal controls to fight fraud, terrorism, other ills. J. Corp. L., 2003. 29: p. 267.

Treba, L., Evaluating internal controls: control self assessment in Government. Journal of Finance and Accounting, 2003. 4(3): p. 55-67.

Reporter, S.S. BOTSWANA SMES STILL FACE CHALLENGES - BIDPA. 2018, Aug 20; Available from: http://www.sundaystandard.info/botswana-smes-still-face-challenges-\%E2\%80\%93-bidpa.

Sankoloba, T. and B. Swami, Impact of internal controls in managing resources of small business: Case study of Botswana. Journal of Small Business and Entrepreneurship Development, 2014. 2(2): p. 87-105.

Zakaria, K.M., A. Nawawi, and A.S.A. Salin, Internal controls and fraud - empirical evidence from oil and gas company. Journal of Financial Crime, 2016. 23(4): p. 1154-1168.

Kinyua, J.K., R. Gakure, and M. Gekara, Orwa, George, Effect of Internal Control Environment on the Financial Performance of Companies Quoted in the Nairobi Securities Exchange. International Journal of Innovative Finance and Economics Research, 2015. 3(4): p. 29-48.

Ncgobo, P. and S.R. Malefane, Internal controls, governance and audit outcomes:Case of a South African municipality. African Journal of Public Affairs, 2017. 9(5): p. 74-89.

LLP, E.Y., Are your internal controls in harmony with your business?, 2017.

Sathyamoorthi, C., Accounting and control systems in selected small and micro enterprises in Botswana. African Journal of Finance and Management, 2001. 10(1): p. 96-109.

Mwakimasinde, M., A. Odhiambo, and J. Byaruhanga, Effects of Internal Control Systems on Financial Performance of Sugarcane out growercompanies inKenya. Journal of Business and Management, 2014. 16(12): p. 62-73. 
Eniola, O., Jacob and O. Akinselure, Phillip, Effect of Internal Control on Financial Performance of Firms in Nigeria. Journal of Business and Management, 2016. 18(10): p. 80-85.

Rittenberg, L.E., F. Martens, and L. Charles, Internal Control Guidance Not Just a Small Matter. Journal of Accountancy, 2007.

Baysinger, B. and R.E. Hoskisson, The Composition of Boards of Directors and Strategic Control: Effects on Corporate Strategy. ? Academy of Management Review, 1990. 15(1): p. 72-87.

Thuy, V., Lifting the Curse of the SOX Through Employee Assessments of the Internal Control Environment. Kansas Law Review, 2007. 56(1).

Botswana, B.o., INTERNAL AUDIT CHARTER - BANK OF BOTSWANA, 2013, March 18.

Ifuzue, A.N., Crime against Retail Business in Botswana. Journal of Social Sciences, 2008. 16(2): p. 91-102.

Eravia, D. and T. Handayani, The opportunities and threats of small and medium enterprises in Pekanbaru: comparison between SMEs in food and restaurant industries. Procedia-Social and Behavioral Sciences, 2015. 169: p. 88-97.

Cooper, D., Business Research Methods2011, new york: mcgraw hill. 